\title{
Retroperitoneal pneumatosis and subcutaneous emphysema after oblique lateral interbody fusion surgery: a case report
}

Chen Liu ${ }^{1,2}$, Yu Zhang ${ }^{1,2}$, Xin Ge ${ }^{1,2}$, Liang Xiao ${ }^{1,2}$ and Hongguang $X u^{1,2^{*}}$

\begin{abstract}
Background: The oblique lateral interbody fusion technique has received increasing attention for the treatment of degenerative disc disease in recent years. A series of complications have been reported, such as vascular injury, sympathetic chain injury, and transient psoas weakness, although it is regarded as a relatively safe technique.

Case presentation: A 55-year-old male patient of Han nationality was diagnosed with lumbar spinal stenosis and underwent standalone oblique lateral interbody fusion surgery under general anethesia. Three days after the operation, subcutaneous gas accumulation appeared in the left lower abdomen of the patient with no inflammatory reaction of the wound. He was treated with conservative management, and the retroperitoneal pneumatosis and subcutaneous emphysema had disappeared completely 1 month later.

Conclusions: To date, this is the first reported case of retroperitoneal pneumatosis and subcutaneous emphysema related to oblique lateral interbody fusion surgery, which broadens the scope of the complications of oblique lateral interbody fusion surgery.
\end{abstract}

Keywords: Retroperitoneal pneumatosis, Subcutaneous emphysema, OLIF surgery, Complications, Case report, Lumbar spinal stenosis

\section{Background}

Oblique lateral interbody fusion (OLIF) is a new technique in which operative access is gained between the abdominal aorta and the psoas major muscle [1]. It is accepted that OLIF not only avoids the excessive traction of large vessels resulting from anterior lumbar interbody fusion (ALIF) but also prevents the destruction of the psoas and lumbar plexus caused by extreme lateral interbody fusion/direct lateral interbody fusion (X/DLIF) [2]. Compared with the most popular posterior lumbar interbody fusion (PLIF) and transforaminal lumbar interbody fusion (TLIF), OLIF can prevent paraspinal muscle

*Correspondence: xuhgyjsyy@163.com

2 Department of Orthopaedics, Yijishan Hospital of Wannan Medical College, No. 2 Zheshan West Road, Wuhu 241001, Anhui, China

Full list of author information is available at the end of the article destruction and dural adhesion [3]. Although the incidence of complications related to this approach is relatively low, some complications have still been reported in previous studies, such as vascular injury, sympathetic chain injury, and transient psoas weakness. To the best of our knowledge, retroperitoneal pneumatosis and subcutaneous emphysema of the abdominal wall after OLIF surgery have not been reported in the literature.

We present a unique case of retroperitoneal pneumatosis and subcutaneous emphysema of the abdominal wall with a noninfectious genesis after OLIF surgery. The patient approved submission of the case for publication.

\section{Case presentation}

A 55-year-old male patient of Han nationality was admitted to our department complaining of numbness and weakness of the lower limbs for more than original author(s) and the source, provide a link to the Creative Commons licence, and indicate if changes were made. The images or other third party material in this article are included in the article's Creative Commons licence, unless indicated otherwise in a credit line to the material. If material is not included in the article's Creative Commons licence and your intended use is not permitted by statutory regulation or exceeds the permitted use, you will need to obtain permission directly from the copyright holder. To view a copy of this licence, visit http://creativecommons.org/licenses/by/4.0/. The Creative Commons Public Domain Dedication waiver (http://creativeco mmons.org/publicdomain/zero/1.0/) applies to the data made available in this article, unless otherwise stated in a credit line to the data. 
5 years and aggravated for 1 month. Lumbar magnetic resonance imaging (MRI) (Fig. 1) indicated that the L4/5 spinal canal was extremely narrow. The patient was diagnosed with lumbar spinal stenosis and underwent stand-alone OLIF surgery under general anesthesia in the right lateral decubitus position. The patient began to practice walking the day after the operation with waist protection, and the symptoms improved. Postoperative lumbar X-ray (Fig. 2) examination showed that the cage was centrally located and that the intervertebral foramen had significantly increased in size. Two days after the surgery, the patient was allowed to be discharged from the hospital with the guidance of strictly wearing waist protection and avoiding bending. Unfortunately, the patient came to our department again complaining of distention of the left lower abdomen 1 day after discharge. The wound did not appear red, and the immediate laboratory test results showed a C-reactive protein (CRP) level of $4.97 \mathrm{mg} / \mathrm{L}$ and an erythrocyte sedimentation rate (ESR) of $13.4 \mathrm{~mm} /$ hour. Furthermore, the patient had no fever. On physical examination, the distension of the lower left abdomen could be palpated. To clarify the abdominal condition, abdominal CT was performed. The results indicated subcutaneous gas accumulation in the left abdominal wall and retroperitoneal pneumatosis, especially around the left kidney (Fig. 3A-D). After consultation, the general surgeon recommended the application of hot compresses to the painful area. The patient was discharged from the hospital 1 week later without any discomfort. One month after the operation, the abdominal CT examination was performed again. No retroperitoneal accumulation or

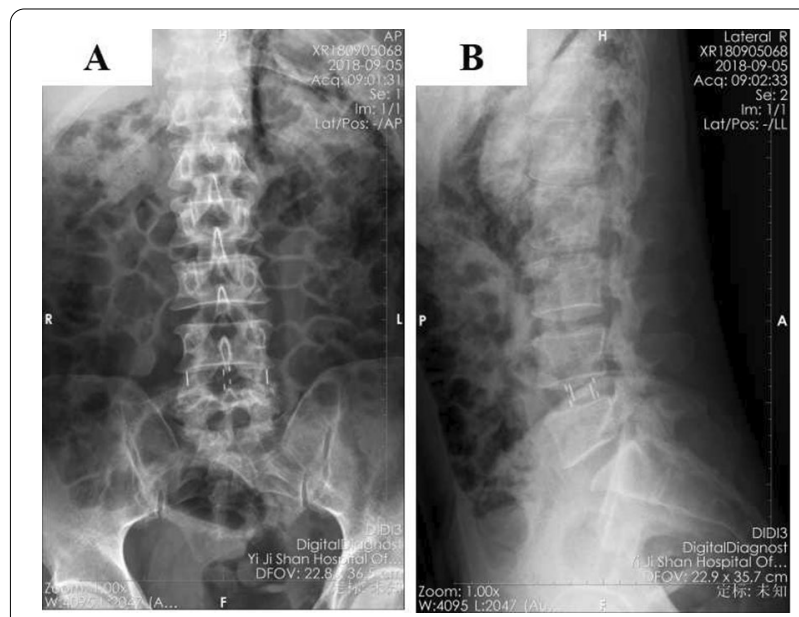

Fig. 2 Positive (A) and lateral (B) X-rays of the lumbar spine after stand-alone OLIF surgery

subcutaneous emphysema of the abdominal wall was found (Fig. 3E-H).

\section{Discussion}

It is widely accepted that OLIF is a relatively safe technology. However, complications are inevitable. Complications can be divided into intraoperative complications and postoperative complications. As reported in previous studies, intraoperative complications include vascular injury, cage subsidence, and vertebral fractures. However, nerve injury, cage subsidence or shifting, and left lower abdominal pain are common postoperative complications [4]. To our knowledge, the current case is the first reported case of retroperitoneal pneumatosis and subcutaneous emphysema of the abdominal wall after OLIF surgery.

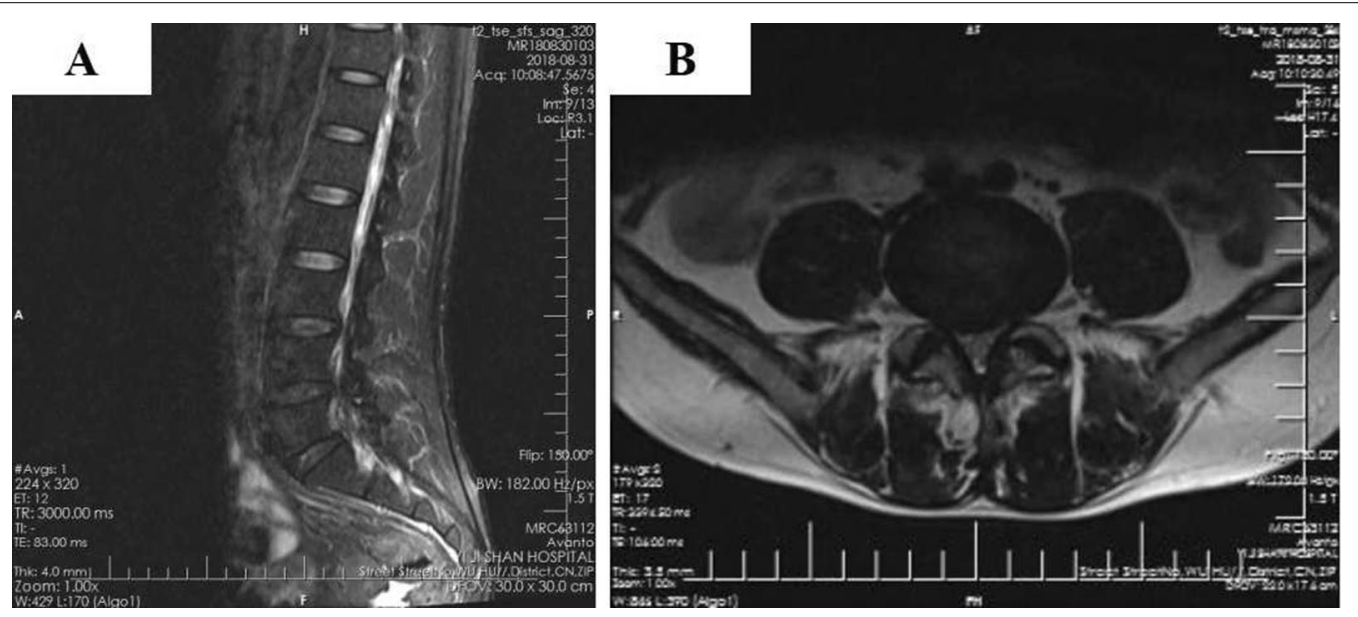

Fig. 1 Sagittal (A) and transverse (B) fat-suppressed MRI of the lumbar spine indicating narrowing of the spinal canal at L4/5 

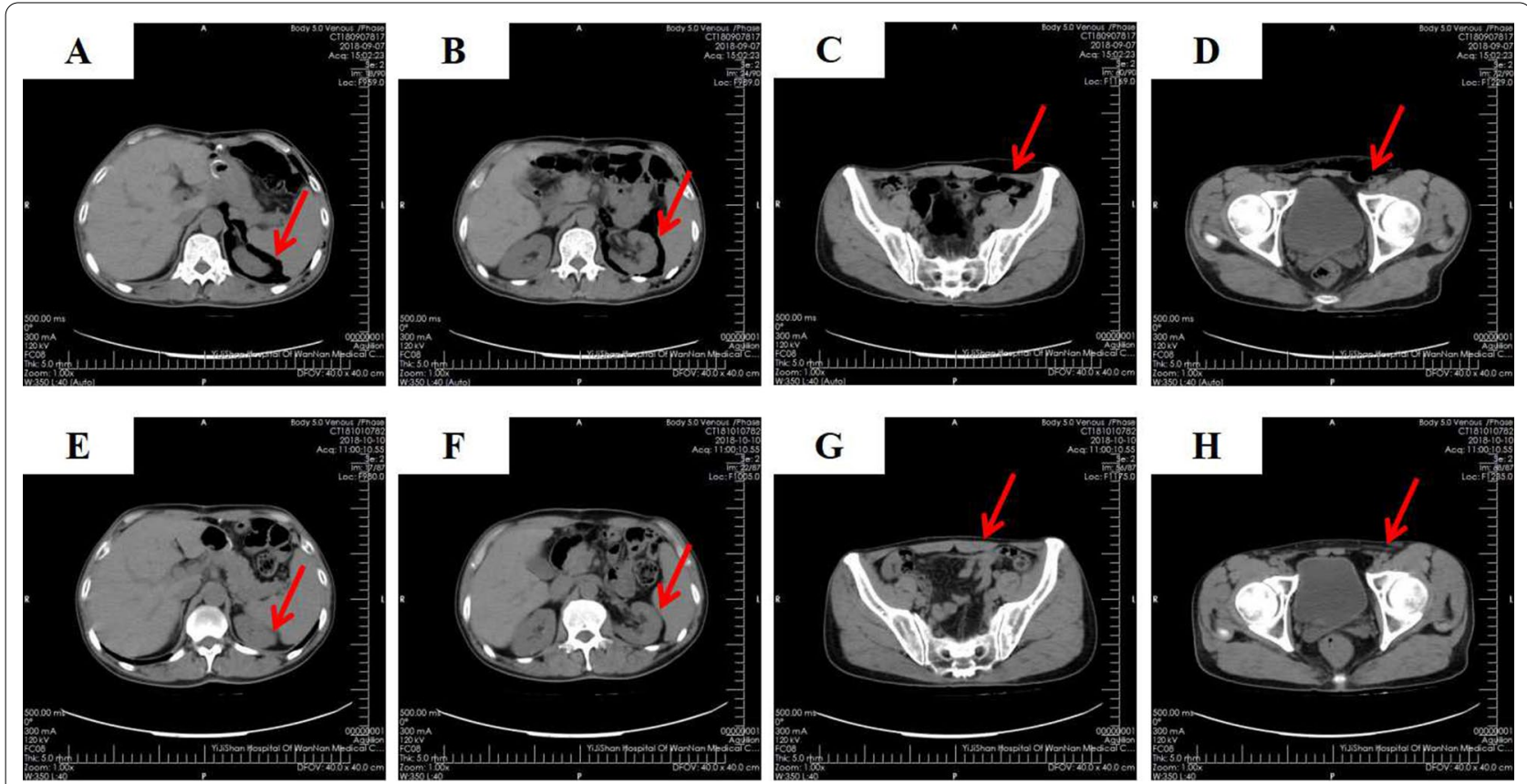

Fig. 3 Perirenal pneumatosis A, B and subcutaneous emphysema of the abdominal wall C, D were obvious on CT 3 days after OLIF surgery (red arrow). One month later, the perirenal pneumatosis $\mathbf{E}, \mathbf{F}$ and subcutaneous emphysema of the abdominal wall $\mathbf{G}, \mathbf{H}$ had almost completely disappeared

It is important to determine the reasons for retroperitoneal pneumatosis and subcutaneous emphysema of the abdominal wall after the operation. In our view, at least three causes should be taken into consideration. First, subcutaneous emphysema is mostly caused by serious infection from gas-forming microorganisms, as demonstrated in previous studies [5]. However, in this case, there were no signs of infection because the white blood cell count and CRP and ESR levels of the patient were normal. In addition, there was no fever, and there was no irritation or inflammation of the wound. Second, the kidney is a retroperitoneal organ. Perirenal pneumatosis mainly originates from a ruptured duodenum [6]. However, the patient showed no signs of peritoneal irritation on physical examination. Moreover, the patient showed no abnormalities in terms of diet or defecation. Finally, the most likely cause of retroperitoneal pneumatosis was air entering the retroperitoneal space during flushing of the operation area. Regarding subcutaneous emphysema of the abdominal wall, on the one hand, retroperitoneal gas could have escaped into the subcutaneous tissue of the left abdominal wall through the fascia of the external oblique abdominal muscle, which was not sutured tightly; on the other hand, premature mobilization could presumably lead to the suction of air into the wound. Julian [7] reported a case of subcutaneous emphysema after elbow arthroscopy caused by joint mobilization. The air was trapped inside and remained in the subcutaneous tissue. Much earlier, Deshmukh [8] demonstrated a case in which early knee mobilization may have led to the suction of air into the knee with every flexion and entrapment of the air in extension after knee arthroscopy. Luckily, the retroperitoneal pneumatosis and subcutaneous emphysema of the abdominal wall in this patient had disappeared 1 month after OLIF surgery without surgical or antibiotic treatment.

\section{Conclusions}

This case highlights the implication that the surgeon should identify the causes of adverse clinical events after an operation and initiate appropriate treatment. Retroperitoneal pneumatosis and subcutaneous emphysema of the abdominal wall could be regarded as a new postoperative complication of OLIF. Patients with retroperitoneal pneumatosis and subcutaneous emphysema of the abdominal wall could be treated conservatively if they have minimal pain and are clinically stable. However, close clinical follow-up should be recommended to avoid life-threatening soft-tissue infection. 


\section{Abbreviations}

ALIF: Anterior lumbar interbody fusion; CT: Computed tomography; DLIF: Direct lateral interbody fusion; MRI: Magnetic resonance imaging; ODI: Oswestry Disability Index; OLIF: Oblique lateral interbody fusion; PLIF: Posterior lumbar interbody fusion; TLIF: Transforaminal lumbar interbody fusion; VAS: Visual analog scale; XLIF: Extreme lateral interbody fusion.

\section{Acknowledgements}

The authors acknowledge support from the National Natural Science Foundation of China.

\section{Authors' contributions}

$\mathrm{CL}$ made substantial contributions to this study. YZ analyzed the MRI and CT images. $X G$ and $L X$ participated in the critical discussion of the contents. $H X$ gave final approval of the manuscript. All authors read and approved the final manuscript.

\section{Funding}

The study was supported by the National Natural Science Foundation of China (81702158 and 81572185), the Foreign Science and Technology Cooperation of Anhui Province (202004b11020027), the "Panfeng" Innovation Team Project for Scientific Research of Yijishan Hospital, Wannan Medical College (PF2019007), and the "Peak"Training Program for Scientific Research of Yijishan Hospital, Wannan Medical College (GF2019T02, GF2019G07, and GF2019G12).

\section{Availability of data and materials}

Not applicable.

\section{Declarations}

Ethics approval and consent to participate

This study was approved by the Ethics Review Committee of Yijishan Hospital of Wannan Medical College. The patient provided consent for participation in this study.

\section{Consent for publication}

Written informed consent was obtained from the patient for publication of the case report and any relevant images. A copy of the written consent is available for review by the Editor-in-Chief of this journal.

\section{Competing interests}

No competing interests exist in the submission of this manuscript.

\section{Author details}

${ }^{1}$ Spine Research Center of Wannan Medical College, No. 2 Zheshan West Road Wuhu 241001, Anhui, China. ${ }^{2}$ Department of Orthopaedics, Yijishan Hospital of Wannan Medical College, No. 2 Zheshan West Road, Wuhu 241001, Anhui, China.

Received: 2 March 2020 Accepted: 1 June 2021

Published online: 31 July 2021

\section{References}

1. Silvestre C, Mac-Thiong JM, Hilmi R, Roussouly P. Complications and morbidities of mini-open anterior retroperitoneal lumbar interbody fusion: oblique lumbar interbody fusion in 179 patients. Asian Spine J. 2012;6(2):89-97.

2. Mehren C, Mayer MH, Zandanell C, et al. The oblique anterolateral approach to the lumbar spine provides access to the lumbar spine with few early complications. Clin Orthop Relat Res. 2016;474(9):2020-7.

3. Deyo RA. Fusion surgery for lumbar degenerative disc disease: still more questions than answers. Spine J. 2015;15(2):272-4.

4. Zeng ZY, Xu ZW, He DW, et al. Complications and prevention strategies of oblique lateral interbody fusion technique. Orthop Surg. 2018;10(2):98-106.

5. Clifford NJ, Katz I. Subcutaneous emphysema complicating renal infection by gas-forming coliform bacteria. A report of two cases in diabetic patients. N Engl J Med. 1962;266(9):437.

6. Yagan N, Auh YA. Extension of air into the right perirenal space after duodenal perforation: CT findings. Radiology. 2009;250(3):740-8.

7. Dexel J, Schneiders W, Kasten P. Subcutaneous emphysema of the upper extremity after elbow arthroscopy. Arthrosc J Arthrosc Relat Surg. 2011;27(7):1014-7.

8. Deshmukh NV, Shaha MM. Extensive subcutaneous emphysema following arthroscopy: a case report. Knee Surg Sports Traumatol Arthrosc. 2002;10:119-21.

\section{Publisher's Note}

Springer Nature remains neutral with regard to jurisdictional claims in published maps and institutional affiliations.
Ready to submit your research? Choose BMC and benefit from:

- fast, convenient online submission

- thorough peer review by experienced researchers in your field

- rapid publication on acceptance

- support for research data, including large and complex data types

- gold Open Access which fosters wider collaboration and increased citations

- maximum visibility for your research: over $100 \mathrm{M}$ website views per year

At $\mathrm{BMC}$, research is always in progress.

Learn more biomedcentral.com/submissions 